\title{
Pilot survey of the health of Massachusetts dentists
}

\author{
Romesh P. Nalliah $^{1,2}$ (D) | Alan Budd ${ }^{3}$ | Veerasathpurush Allareddy ${ }^{4}$
}

${ }^{1}$ School of Dentistry, University of Michigan, Ann Arbor, MI, USA

${ }^{2}$ Harvard School of Dental Medicine, Boston, MA, USA

${ }^{3}$ Massachusetts Dental Society, Southborough, MA, USA

${ }^{4}$ Department of Orthodontics, University of lowa, lowa City, IA, USA

Correspondence

Dr Romesh P. Nalliah, University of Michigan School of Dentistry, Ann Arbor, MI, USA.

Email: romeshn@umich.edu

\begin{abstract}
Aim: Dentistry is a career that is very rewarding because of the direct opportunity to deliver essential health services to patients in need. Dentistry is also very demanding; mentally, physically, and even emotionally. Little is known about the health of dentists and how it compares to the health of the general population. The aim of the present study was to report on the general health and health practices of dentists in Massachusetts.

Methods: A medical health and health practices survey was developed from the Delaware Valley Community Health Center and customized. The surveys contained 36 questions relating to demographics, general health, and health practices.

Results: A total of 399 dentists completed the survey. Of those who responded to the survey, $78.2 \%$ were males, $32.6 \%$ were $56-65$ years of age, $23.1 \%$ were $66-75$ years of age, and $21.6 \%$ were $46-55$ years of age.

Conclusion: This pilot study highlights several health issues where dentists seem to have a lower incidence than the general population: asthma, depression, diabetes, hearing loss, obesity, smoking, sleep apnea, and thyroid disease. However, there are some health issues where dentists have a higher incidence than the general population: taking at least one prescription medication, gastroesophageal reflux disease, some form of cancer, back pain, neck pain, headache, osteoarthritis, rheumatic arthritis, psoriatic arthritis, and alcohol abuse.
\end{abstract}

\section{KEYWORDS}

dental profession, general health, health practice, Massachusetts, stress

\section{1 | INTRODUCTION}

Various careers have certain physical and mental demands that can lead to harm and health problems. For example, a career that requires a lot of keyboard typing increases the risk of carpal tunnel syndrome. ${ }^{1}$ The dental profession is also associated with certain conditions, such as hearing loss and back pain. However, there has not been a major study among dentists to evaluate health and health practices.

We collaborated with the Dentist Health and Wellness Committee (DHWC) of the Massachusetts Dental Society (MDS) to develop, validate, and administer a survey evaluating the general health and health practices of dentists in Massachusetts, USA. The objective of the survey was to serve as pilot data to identify areas of health concern for member dentists that the MDS that DHWC could address by developing innovative programming and resources for their membership. Traditionally, dental societies have provided continuing education credit and opportunities to network; however, we believe that these services could evolve to include health screenings, stress management workshops, and even yoga. The MDS is a strong association and has close to $80 \%$ of Massachusetts dentists as its members. The findings from the current study could highlight common health concerns of dentists and serve as a foundation for innovative and new approaches for state dental societies to serve their members. 


\section{2 | MATERIALS AND METHODS}

Health surveys were developed by two of the authors (RPN and VA) by beginning with the medical history form from Delaware Valley Community Health Center and customizing it. The customized forms were then further edited by another author $(A B)$, and then validated by members of the DHWC of MDS. The surveys contained 36 questions relating to demographics, general health, and health practices. Institutional review board approval was acquired prior to administering the survey through the Harvard Medical School Committee on Human Studies.

The MDS sent surveys electronically to all Massachusetts member dentists who had provided their email address ( $n=3957$ individuals). One reminder was sent 3 months later, and there was no incentive offered. Simple descriptive statistics were utilized to demonstrate findings.

\section{3 | RESULTS}

A total of 399 dentists completed the survey of the 3957 who received an email inviting them to participate. This represents a response rate of $10.1 \%$. Of those who responded to the survey, $78.2 \%$ were males, $32.6 \%$ were $56-65$ years of age, $23.1 \%$ were $66-75$ years of age, and $21.6 \%$ were $46-55$ years of age. The demographic information is shown in Table 1.

The cardiovascular complaints are shown in Table 2; 59.3\% of dentists reported no cardiovascular disease, $29.7 \%$ reported hypertension, and $4 \%$ reported a heart murmur.

All endocrine disorders are shown in Table 3; $79 \%$ of dentists reported no disease. However, $4.5 \%$ reported a thyroid malfunction and $3.5 \%$ reported type 2 diabetes.

Reported respiratory conditions are shown in Table 4; 6.5\% had sleep apnea, 5.8\% had asthma, and $79.8 \%$ had no respiratory problem. Digestive complaints are also shown in Table 4; $15 \%$ had gastroesophageal reflux disease, $6.5 \%$ had other digestive problems, and $70.5 \%$ reported no digestive problems.

All reported immune and arthritic diseases and cancer are shown in Table 5; $18 \%$ had osteoarthritis and only $67.5 \%$ reported not having any arthritis. Additionally, $6.6 \%$ of males had prostate cancer, $3.6 \%$ of females had breast cancer, and $81 \%$ reported no cancer.

Reported psychiatric conditions are presented in Table 6. These included drug use/dependence and medication use. In this Table, it can be seen that $6.5 \%$ had depression and $6 \%$ had anxiety disorders. Additionally, $2.3 \%$ reported alcohol abuse, $0.3 \%$ reported prescription drug abuse, $8 \%$ had more than 10 alcoholic drinks/week, and $0.5 \%$ smoked one-to-10 cigarettes/week. Finally, only 34.8\% did not take medication. A total of $30.3 \%$ took medication for cholesterol, and $28.7 \%$ took medications for hypertension.

Contagious diseases and other conditions are shown in Table 7; $34.3 \%$ reported back pain, $8.5 \%$ reported headaches, and $5.8 \%$ reported deafness or partial deafness.
TABLE 1 Demographics of study participants

\begin{tabular}{|c|c|c|}
\hline Characteristic & Response & $\begin{array}{l}\text { Respondents } \\
\text { (\%) }\end{array}$ \\
\hline \multirow[t]{2}{*}{$\operatorname{Sex}(n=385)$} & Male & 78.2 \\
\hline & Female & 21.8 \\
\hline \multirow[t]{7}{*}{ Age $(n=389)$} & $20-25$ y & 0 \\
\hline & $26-35$ y & 6.2 \\
\hline & $36-45 y$ & 9.3 \\
\hline & $46-55 y$ & 21.6 \\
\hline & $56-65$ y & 32.6 \\
\hline & $66-75$ y & 23.1 \\
\hline & $76+y$ & 7.2 \\
\hline \multirow{5}{*}{$\begin{array}{l}\text { Marital status } \\
(n=391)\end{array}$} & Single & 7.7 \\
\hline & Married & 80.8 \\
\hline & Divorced & 6.4 \\
\hline & De facto & 0.8 \\
\hline & Other & 4.3 \\
\hline \multirow{10}{*}{$\begin{array}{l}\text { Specialty } \\
\text { training } \\
(n=388)\end{array}$} & Dental public health & 0.5 \\
\hline & Endodontics & 2.1 \\
\hline & General dentistry & 78.6 \\
\hline & Oral and maxillofacial pathology & 0.5 \\
\hline & Oral and maxillofacial radiology & 0 \\
\hline & Oral and maxillofacial surgery & 4.6 \\
\hline & Orthodontics & 4.6 \\
\hline & Pediatric dentistry & 3.9 \\
\hline & Periodontics & 1.8 \\
\hline & Prosthodontics & 3.4 \\
\hline \multirow{7}{*}{$\begin{array}{l}\text { Practice setting } \\
(n=386)\end{array}$} & Solo private practice dentist & 50.3 \\
\hline & Group private practice dentist & 33.2 \\
\hline & Corporate dental group & 1.8 \\
\hline & Community health center dentist & 2.8 \\
\hline & Full-time academic appointment & 2.8 \\
\hline & Military dentist & 0 \\
\hline & Other & 9.1 \\
\hline \multirow{7}{*}{$\begin{array}{l}\text { How long have } \\
\text { you been } \\
\text { practicing } \\
\text { your } \\
\text { specialty? } \\
\text { ( } n=385)\end{array}$} & $<1 \mathrm{y}$ & 1.3 \\
\hline & $>1$, but $<3$ y & 2.3 \\
\hline & $>3$, but $>5$ y & 2.6 \\
\hline & $>5$, but $<7$ y & 1.3 \\
\hline & $>7$, but $<9$ y & 1.8 \\
\hline & $>9$, but $<20$ y & 11.7 \\
\hline & $>20 y$ & 79 \\
\hline
\end{tabular}

Other health practices are presented in Table 8; 53\% reported walking regularly; $43.8 \%$ reported regular exercise outdoors; $42 \%$ reported regular exercise at the gym; $29.8 \%$ reported regularly going to church, temple, mosque, or another religious institution; and $23.5 \%$ reported regularly playing a sport.

Information about last physical examination is presented in Table 9; $6.2 \%$ reported having had their last physical examination $1.5-3$ years 
TABLE 2 Cardiovascular conditions

\begin{tabular}{|lc|}
\hline Cardiovascular conditions & $\begin{array}{l}\text { Respondents, } \boldsymbol{n} \\
\text { (\%) }\end{array}$ \\
\hline Arteriosclerosis & $15(3.8)$ \\
\hline Abnormal pulse & $12(3)$ \\
\hline High blood pressure & $117(29.3)$ \\
\hline Heart murmur & $17(4.3)$ \\
\hline Valve defect & $7(1.8)$ \\
\hline Circulatory disorder & 0 \\
\hline Vascular disorder & $1(0.3)$ \\
\hline Stroke & $3(0.8)$ \\
\hline Other cardiovascular problem & $15(3.8)$ \\
\hline No cardiovascular disease & $237(59.3)$ \\
\hline
\end{tabular}

TABLE 3 Endocrine conditions

\begin{tabular}{|lc|}
\hline Endocrine conditions & $\begin{array}{l}\text { Respondents, } \boldsymbol{n} \\
(\%)\end{array}$ \\
\hline Diabetes & $12(3)$ \\
\hline Thyroid malfunction & $18(4.5)$ \\
\hline Addison's disease & 0 \\
\hline Diabetes type 1 & $4(1)$ \\
\hline Diabetes type 2 & $14(3.5)$ \\
\hline Adrenal hormone excess & 0 \\
\hline Pituitary gland disorder & $2(0.5)$ \\
\hline Sex hormone disorder & $3(0.8)$ \\
\hline Obesity & $33(8.3)$ \\
\hline Other endocrine problem & $5(1.3)$ \\
\hline No endocrine disease & $316(79)$ \\
\hline
\end{tabular}

TABLE 4 Respiratory and digestive conditions

\begin{tabular}{|l|c|}
\hline Conditions & $\begin{array}{l}\text { Respondents, } n \\
(\%)\end{array}$ \\
\hline Respiratory conditions & $23(5.8)$ \\
\hline Asthma & $2(0.5)$ \\
\hline Bronchitis & $26(6.5)$ \\
\hline Sleep apnea & $2(0.5)$ \\
\hline Lung disease & $3(0.8)$ \\
\hline Other respiratory condition & $319(79.8)$ \\
\hline No respiratory disease & \\
\hline Digestive disease & $60(15)$ \\
\hline Gastroesophageal reflux disease & $7(1.8)$ \\
\hline Gastritis & $2(0.5)$ \\
\hline Peptic (gastric) ulceration & 0 \\
\hline Pyloric stenosis & $2(0.5)$ \\
\hline Kidney disease & $1(0.3)$ \\
\hline Liver disease & 0 \\
\hline Spleen disease & $26(6.5)$ \\
\hline Other digestive problem & $282(70.5)$ \\
\hline No digestive problem & \\
\hline
\end{tabular}

TABLE 5 immune and autoimmune diseases and cancer

\begin{tabular}{|lc|}
\hline Diseases & Respondents, $n$ (\%) \\
\hline Immune diseases & \\
\hline Lupus & 0 \\
\hline Scleroderma & 0 \\
\hline Vasculitis & 0 \\
\hline Connective tissue disease & 0 \\
\hline HIV & 0 \\
\hline Other immune disease & $6(2.3)$ \\
\hline No immune disease & $355(88.8)$ \\
\hline Arthritic conditions & \\
\hline Osteoarthritis & $72(18)$ \\
\hline Rheumatoid arthritis & $5(1.3)$ \\
\hline Osteoporosis & $5(1.3)$ \\
\hline Psoriatic arthritis & $5(1.3)$ \\
\hline Other arthritic condition & $24(6)$ \\
\hline No arthritic condition & $270(67.5)$ \\
\hline Cancer & \\
\hline Prostate cancer & $20(6.6 \%$ of males) \\
\hline Breast cancer & $3(3.6 \%$ of females) \\
\hline Oral cancer & 0 \\
\hline Leukemia & $2(0.5)$ \\
\hline Lymphoma & $2(0.5)$ \\
\hline Other cancer & \\
\hline No cancer & \\
\hline & \\
\hline
\end{tabular}

ago, $9.5 \%$ reported to have had it $1-1.5$ years ago, 31\% reported to have had it 6 months- 1 years ago, and $51 \%$ reported to have had it within 6 months. The obstacles faced by Massachusetts dentists in accessing medical care is also shown in this Table, where $37 \%$ reported time as the major barrier, and $7.8 \%$ reported cost as the major barrier.

\section{DISCUSSION}

The demographics of the Massachusetts dentists in the current study closely resemble the demographics of US dentists. In the current study, $6 \%$ were $26-35$ years old, $9 \%$ were $36-45$ years old, $22 \%$ were 46-55 years old, $33 \%$ were $56-65$ years old, $23 \%$ were $66-75$ years, and $7.2 \%$ were over 75 years. This is similar to American Dental Association (ADA) data for all of the USA. ${ }^{2}$ It is notable that over $30 \%$ of responders in the current study were 56 years or older, and ADA data show that over $37 \%$ are 55 years or over. ${ }^{2}$ This concurs with previous research that shows the dental workforce is an aging population. ${ }^{3}$

The current study included $78.2 \%$ males, while existing ADA data show that the dentist workforce is $77.8 \%$ males. ${ }^{2}$ Additionally, our study included $78.6 \%$ general dentists, and the ADA data show that, nationally, $78.8 \%$ of dentists are general dentists and $21.2 \%$ are specialist dentists. ${ }^{2}$ Finally, the current study captured $50.3 \%$ in solo practice and $33.2 \%$ in group practices. These figures are very similar to existing literature, which shows that $38.5 \%$ work in a practice with one-to-four employees, 
TABLE 6 Psychiatric conditions, and drug and medication use

\begin{tabular}{|c|c|}
\hline Psychiatric conditions & $\begin{array}{l}\text { Respondents, } n \\
\text { (\%) }\end{array}$ \\
\hline Depression & $26(6.5)$ \\
\hline Adjustment disorder & $1(0.3)$ \\
\hline Affective disorder & $2(0.5)$ \\
\hline Anxiety disorder & $24(6)$ \\
\hline Obsessive compulsive disorder & $2(0.5)$ \\
\hline Epilepsy & $1(0.3)$ \\
\hline Other psychiatric problem & $3(0.8)$ \\
\hline No psychiatric health conditions & $333(83.3)$ \\
\hline \multicolumn{2}{|l|}{ Conditions related to substance use } \\
\hline Alcohol abuse & $9(2.3)$ \\
\hline Prescription drug abuse & $1(0.3)$ \\
\hline Illicit drug abuse & 0 \\
\hline Smoke cigarettes and want to quit & $2(0.5)$ \\
\hline Smoke cigarettes and do not want to quit & 0 \\
\hline None of the above conditions & $328(82)$ \\
\hline Consume 1-10 alcoholic beverages/wk & $223(55.8)$ \\
\hline Consume $>10$ alcohol beverages/wk & $32(8)$ \\
\hline Smoke $1-10$ cigarettes/wk & $2(0.5)$ \\
\hline Smoke up to 1 pack of cigarettes/wk & 0 \\
\hline Smoke $>1$ pack of cigarettes/wk & 0 \\
\hline Smoke other substances on a weekly basis & $8(2)$ \\
\hline \multicolumn{2}{|l|}{ Medication use and reason } \\
\hline Cholesterol & $121(30.3)$ \\
\hline Depression & $25(6.3)$ \\
\hline Diabetes & $16(4)$ \\
\hline Hypertension & $115(28.7)$ \\
\hline Thyroid function & $22(5.5)$ \\
\hline Other medication & $103(25.8)$ \\
\hline Not taking medication & $139(34.8)$ \\
\hline
\end{tabular}

$38.4 \%$ with four-to-nine employees, $19.2 \%$ with $10-19$ employees, $3.6 \%$ with 20-29 employees, and 0.22\% with more than 50 employees. ${ }^{4}$ In summary, the demographics and practice setting of the dentists who responded to our survey are similar to US dentists, and our pilot data could be useful in understanding the health of dentists in the USA.

Our study found that $42 \%$ of Massachusetts dentists exercised regularly at a gym. Additionally, $43.8 \%$ exercised regularly outside, and $53 \%$ walked regularly; however, the Massachusetts winters are harsh, and one wonders how regularly these outdoor activities are maintained during the colder months of the year (the survey was administered in September 2013).

When describing barriers that inhibit them acquiring the healthcare services they require, $37 \%$ of Massachusetts dentists cite lack of time. This is very surprising and ironic given that a balanced lifestyle and autonomy are two commonly-cited reasons for pursuing dentistry as a career. ${ }^{5,6}$ It would appear that dentists have forgotten some of the values that attracted them to their career in the first place.
TABLE 7 Contagious diseases and other conditions

\begin{tabular}{|l|l|}
\hline Diseases and conditions & $\begin{array}{l}\text { Respondents, } \boldsymbol{n} \\
(\%)\end{array}$ \\
\hline Contagious diseases & \\
\hline Tuberculosis & 0 \\
\hline Hepatitis A & 0 \\
\hline Hepatitis B & 0 \\
\hline Hepatitis C & $1(0.3)$ \\
\hline Ringworm & 0 \\
\hline Giardiasis & $5(1.3)$ \\
\hline Other conditions & \\
\hline Multiple sclerosis & $1(0.3)$ \\
\hline Epilepsy & $1(0.3)$ \\
\hline Paralysis or partial paralysis & $1(0.3)$ \\
\hline Blindness or partial blindness & $3(0.8)$ \\
\hline Deafness or partial deafness & $23(5.8)$ \\
\hline Back pain & $289(72.4)$ \\
\hline Neck pain & $186(46.6)$ \\
\hline Headaches & $71(17.8)$ \\
\hline Facial pain & $8(2)$ \\
\hline None of the above & $194(48.5)$ \\
\hline
\end{tabular}

TABLE 8 Other relevant health statements

\begin{tabular}{|lc|}
\hline Statements & $\begin{array}{l}\text { Respondents, } \boldsymbol{n} \\
(\%)\end{array}$ \\
\hline I have medical insurance & $385(96.3)$ \\
\hline I have dental insurance & $63(15.8)$ \\
\hline I regularly exercise at the gym & $168(42)$ \\
\hline I regularly exercise outside & $175(43.8)$ \\
\hline I regularly participate in yoga classes & $28(7)$ \\
\hline I regularly participate in Pilates classes & $13(3.3)$ \\
\hline I regularly have a massage & $57(14.2)$ \\
\hline I regularly ride a bicycle & $72(18)$ \\
\hline I regularly play a sport & $94(23.5)$ \\
\hline I regularly dance & $7(1.8)$ \\
\hline I regularly walk & $212(53)$ \\
\hline I regularly meet with a counselor, therapist, or & $21(5.3)$ \\
\hline other mental health worker & $119(29.8)$ \\
\hline I regularly go to church, temple, mosque, or & $20(5)$ \\
\hline another religious institution & \\
\hline Other &
\end{tabular}

\subsection{Conditions where dentists have lower prevalence than the general population}

Obesity is an epidemic in the USA, and 34\% of Americans are obese. ${ }^{7}$ The current study of Massachusetts dentists found that only $9 \%$ of dentists reported being obese. Diabetes can be a related condition, and only $5 \%$ of Massachusetts dentists reported having diabetes 
TAB LE 9 Last physical examination, and obstacles in seeking health care

\begin{tabular}{|l|l|}
$\begin{array}{l}\text { Physical examination with a primary care } \\
\text { physician }\end{array}$ & $\begin{array}{l}\text { Respondents, } \boldsymbol{n} \\
(\%)\end{array}$ \\
\hline$<6$ mo ago & $199(51)$ \\
\hline $6-12$ mo ago & $120(31)$ \\
\hline $1-1.5$ y ago & $37(9.5)$ \\
\hline $1.5-3$ y ago & $24(6.2)$ \\
\hline $3-5$ y ago & $5(1.3)$ \\
\hline $5-8$ y ago & $3(0.8)$ \\
\hline$>8$ y ago & $1(0.3)$ \\
\hline $\begin{array}{l}\text { Never had a physical examination with a primary } \\
\text { care physician that I can remember }\end{array}$ & 0 \\
\hline $\begin{array}{l}\text { Obstacles } \\
\text { Cost }\end{array}$ & $31(7.8)$ \\
\hline Time & $148(37)$ \\
\hline $\begin{array}{l}\text { Geographic location - there are no physicians } \\
\text { nearby }\end{array}$ & $6(1.5)$ \\
\hline $\begin{array}{l}\text { Physician/dentist skill - the physician/dentist } \\
\text { nearby cannot manage my medical/dental } \\
\text { concerns }\end{array}$ & $7(1.8)$ \\
\hline \begin{tabular}{l} 
Other \\
\hline
\end{tabular} & $13(3.3)$ \\
\hline
\end{tabular}

compared with $8.3 \%$ of the US population. ${ }^{8}$ Obesity can be related to sleep apnea, and 7\% of Massachusetts dentists have this condition, which is the same proportion as the general US population. ${ }^{9}$

Although research is inconclusive, links between obesity and thyroid disease have been suggested. ${ }^{10}$ This would imply that Massachusetts dentists (who have lower obesity rates) might be less likely to suffer from thyroid disease. Data from the American Thyroid Association show that $6.4 \%$ of Americans have some form of thyroid disease; ${ }^{11}$ however, only $4.5 \%$ of Massachusetts dentists reported having a thyroid disease.

Asthma is a common chronic disease, and $6 \%$ of Massachusetts dentists reported having asthma compared to $8.4 \%$ of the general US population. ${ }^{12}$ Asthma can be associated with smoking, which is a common habit, and $18.1 \%$ of Americans smoke cigarettes; ${ }^{13}$ however, only $1 \%$ of Massachusetts dentists smoke. Additionally, recent research shows that asthma might also be associated with obesity, which is another health condition that Massachusetts dentists do not seem to suffer from in high volumes. ${ }^{14}$

In our pilot study of Massachusetts dentists, 7\% reported suffering from depression compared to $9.1 \%$ among the general population. ${ }^{15}$ It is notable that existing research suggests that only $15 \%$ of depressed dentists were receiving the treatment they needed. This could indicate that it is an underreported condition among dentists. ${ }^{16}$

In the current study,12\% of dentists reported some hearing loss compared to $20.3 \%$ among the general population who suffer hearing loss. ${ }^{17}$ This is an interesting finding because a large amount of media coverage and research suggests that hearing loss is an occupational hazard for dentists. ${ }^{18-20}$ A previous study among Flemish dentists found that $19.6 \%$ suffered auditory disorders. ${ }^{21}$ This suggests that
Massachusetts dentists seem to have better hearing outcomes than other dentists and the general population. However, our pilot study also found several conditions where dentists seemed to have poorer health outcomes than the general population.

\subsection{Conditions where dentists have similar or higher prevalence than the general population}

In the current study of Massachusetts dentists, $64 \%$ took at least one prescription drug compared to a rate of only $50 \%$ in the general population. ${ }^{22}$ Gastroesophageal reflux disease is associated with a prevalence rate of $10-20 \%$ of the general population. ${ }^{23}$ Among Massachusetts dentists, the prevalence is toward the upper end, with $16 \%$.

Cancer is a pervasive disease, and the National Cancer Institute reports that $4.1 \%$ of general population have had some form of cancer. ${ }^{24}$ However, $13 \%$ of Massachusetts dentists report having had some form of cancer, which is more than triple the rate among the general population. More research is necessary in this area to consider whether some occupational factor impacts cancer rates among dentists.

A surprising finding was that $72.4 \%$ of the Massachusetts dentists surveyed had suffered back pain. This compares very unfavorably to the general population, where prevalence rates are as low as $6.3-26.4 \%{ }^{25,26}$ Additionally, the prevalence of neck pain among dentists in our study was $47 \%$ compared to general population findings, which vary from $13.8 \%$ to $23.1 \%{ }^{25,26}$ Interestingly, previous research among dentists uncovered an identical rate of $47 \%$ of dentists with neck pain. ${ }^{27}$ The current study also demonstrated that $17.8 \%$ of the Massachusetts dentists surveyed reported suffering from headaches, whereas $16.6 \%$ of adults in the general population report experiencing headaches. $^{28}$

Existing research has demonstrated that postures preferred by dentists as a way to relieve back stress could actually contribute to the development of shoulder or neck musculoskeletal disorders due to raised trapezius exertions. ${ }^{29}$ Alternative, evidence-based approaches to human movement, such as the Alexander Technique, that focus on the more efficient use of the back, shoulders, and arms, might help prevent and alleviate back and neck symptoms for dentists. $^{30}$

When considering osteoarthritis, $12.1 \%$ of the general population have this condition compared with $19 \%$ of Massachusetts dentists in the current study. ${ }^{31}$ In the case of rheumatoid arthritis, $1.3 \%$ of Massachusetts dentists reported this condition, whereas the National Institute of Arthritis and Musculoskeletal and Skin Diseases report that only $0.6 \%$ of the general population have this disease. ${ }^{32}$ Approximately $0.25 \%$ of the general population has psoriatic arthritis; ${ }^{33}$ however, $1.3 \%$ of dentists reported suffering from this condition. Our study also found that $1.3 \%$ of dentists reported having osteoporosis; however, the American Academy of Orthopaedic Surgeons states that approximately $3.2 \%$ of Americans have this condition. ${ }^{34}$ It should be noted that the dental profession is largely made up of males (our study comprised $78.2 \%$ males), and males have a lower risk for osteoporosis. ${ }^{35}$ This could explain why our data showed such a low occurrence of osteoporosis among dentists in Massachusetts. 
However, the higher rates of various types of arthritis warrant further research into whether occupational factors increase the risk of these conditions among dentists.

Finally, existing Gallup poll data demonstrate that $12 \%$ of the general population consume more than eight alcoholic drinks/week. ${ }^{36}$ In the current study of Massachusetts dentists, $8 \%$ drank more than 10 drinks/week, and 2.3\% reported alcohol abuse. In the USA, 7.2\% of adults have alcohol use disorders. ${ }^{37}$ Dentists largely operate independently, and we depend on them to self-identify and resolve gaps in knowledge, skills, and alcohol dependence (to name a few). It is important for dental societies and dental registration boards to have non-judgmental support mechanisms for dentists, and create a safe environment for self-reporting. Dentistry is a stressful career, and there is extensive research on how stressful the profession is. ${ }^{38,39}$ There is even evidence that dentists can transmit this stress to their dental assistants. ${ }^{40}$ Previous research among dentists has shown that alcohol use is associated with work stress. ${ }^{41}$ Another study of 256 dentists found that 219 had high chronic stress. ${ }^{42}$ What is important to consider is that all of the conditions where dentists have similar or higher prevalence than the general population have been associated with stress: alcohol consumption, prescription drug use, back pain, neck pain, headache, osteoarthritis, and gastroesophageal reflux disease, and there is even some evidence that cancer is related to stress. ${ }^{43-49}$ Hypertension is also associated with stress, and the current study revealed that $29.3 \%$ of Massachusetts dentists reported suffering hypertension (and $28.7 \%$ take medication for hypertension).

Dentists seem to suffer from a higher prevalence of several health conditions that could severely hinder their quality of life and lead to premature death. Even more troubling is the finding that Massachusetts dentists do not always have good health practices. For instance, $18 \%$ of dentists in the current study did not have a physical examination within the past 12 months. A further $2.3 \%$ had not had a physical examination within the last 3 years. A total of $96.3 \%$ of dentists had medical insurance, but health-care utilization was lower; only $82 \%$ used their insurance benefit to have a physical examination in the past 12 months.

It should be noted that there are several limitations of our pilot study. First, the responses of all dentists were self-reported and subject to error and bias. We did not measure any health conditions, but relied on dentists to report their own health conditions. It is possible that some conditions were underreported or overreported. Moreover, the response rate was low, and information might not be generalizable. However, Survey Gizmo (the survey design tool) states that a $10-15 \%$ survey response rate for an "external", "online" survey with "no incentive" is an expected result. ${ }^{50}$ As described earlier, the characteristics of the dentists who responded to our survey are very similar to the characteristics of dentists nationwide.

\section{5 | CONCLUSION}

Our study of Massachusetts dentists found that dentists have a higher incidence of various health conditions, and many of these conditions have been associated with stress in the current literature. Additionally, our study shows that dentists are suboptimal utilizers of health-care services.

\section{REFERENCES}

1. Shafer-Crane GA, Meyer RA, Schlinger MC, Bennett DL, Robinson $\mathrm{KK}$, Rechtien JJ. Effect of occupational keyboard typing on magnetic resonance imaging of the median nerve in subjects with and without symptoms of carpal tunnel syndrome. Am J Phys Med Rehabil. 2005;84:258-266

2. American Dental Association. Supply of dentists. http://www.ada. org/en/science-research/health-policy-institute/data-center/supply-of-dentists. Accessed September 16, 2015.

3. Department of Labor. The aging workforce: challenges for the health care industry workforce. http://www.dol.gov/odep/pdf/NTARAgingWorkforceHealthCare.pdf. Accessed April 10, 2016.

4. Waldman H, Perlman S. Mapping dental establishments in Massachusetts just before the recession. J Mass Dent Soc. 2010;59:34-37.

5. American Dental Association. Be a dentist. http://www.ada.org/ en/education-careers/careers-in-dentistry/be-a-dentist. Accessed September 16, 2015

6. Hallissey J, Hannigan A, Ray N. Reasons for choosing dentistry as a career-a survey of dental students attending a dental school in Ireland during 1998-1999. Eur J Dent Educ. 2000;4:77-81.

7. Center for Disease Control and Prevention. Adult obesity facts. http:// www.cdc.gov/obesity/data/adult.html. Accessed April 14, 2016.

8. Center for Disease Control and Prevention. http://www.ada.org/en/ education-careers/careers-in-dentistry/be-a-dentist. Accessed April 28, 2016

9. American Sleep Apnea Association. Sleep apnea information for clinicians. http://www.sleepapnea.org/i-am-a-health-care-professional. html. Accessed May 1, 2016.

10. Nyrnes A, Jorde R, Sundsfjord J. Serum TSH is positively associated with BMI. Int J Obes (Lond). 2006;30:100-105.

11. American Thyroid Association. General information/press room. http://www.thyroid.org/media-main/about-hypothyroidism/. Accessed May 1, 2016.

12. Center for Disease Control and Prevention. Trends in asthma prevalence, health care use, and mortality in the United States, 2001-2010. http://www.cdc.gov/nchs/data/databriefs/db94.htm. Accessed June 20, 2016.

13. Center for Disease Control and Prevention. Current cigarette smoking among adults in the United States. http://www.cdc.gov/tobacco/data statistics/fact_sheets/adult_data/cig_smoking/. Accessed June 20, 2016

14. Boulet LP. Asthma and obesity. Clin Exp Allergy. 2013;43:8-21. doi:10.1111/j.1365-2222.2012.04040.x.

15. Center for Disease Control and Prevention. https://www.cdc.gov/ nchs/data/databriefs/db172.htm. Accessed June 20, 2016.

16. Mathias S, Koerber A, Fadavi S, Punwani I. Specialty and sex as predictors of depression in dentists. J Am Dent Assoc. 2005;136:1388-1395.

17. Lin FR, Niparko JK, Ferrucci L. Hearing loss prevalence in the United States. Arch Intern Med. 2011:171:1851-1852.

18. Hear-It. Your dentist should be concerned with hearing as well as teeth. http://www.hear-it.org/Dentists-and-hearing-loss. Accessed October 10, 2016.

19. Singh S, Gambhir RS, Singh G, Sharma S, Kaur A. Noise levels in a dental teaching institute - A matter of concern! J Clin Exp Dent. 2012;4:e141-e145.

20. Ayatollahi J, Ayatollahi F, Ardekani AM, et al. Occupational hazards to dental staff. Dent Res J. 2012;9:2-7.

21. Gijbels F, Jacobs R, Princen K, Nackaerts O, Debruyne F. Potential occupational health problems for dentists in Flanders, Belgium. Clin Oral Investig. 2006;10:8-16. 
22. Center for Disease Control and Prevention. Therapeutic drug use. http://www.cdc.gov/nchs/fastats/drugs.htm. Accessed June 24, 2016.

23. Badillo R, Francis D. Diagnosis and treatment of gastroesophageal reflux disease. World J Gastrointest Pharmacol Ther. 2014;5:105-112.

24. National Cancer Institute. Cancer stat facts: cancer of any site. http:// seer.cancer.gov/statfacts/html/all.html. Accessed November 4, 2016.

25. Hoy D, Brooks P, Blyth F, Buchbinder R. The epidemiology of low back pain. Best Pract Res Clin Rheumatol. 2010;24:769-781.

26. Deyo RA, Mirza SK, Martin BI. Back pain prevalence and visit rates: estimates from U.S. national surveys, 2002. Spine (Phila Pa 1976). 2006;23:2724-2727.

27. Kierklo A, Kobus A, Jaworska M, Botuliński B. Work-related musculoskeletal disorders among dentists - a questionnaire survey. Ann Agric Environ Med. 2011;18:79-84.

28. Smitherman TA, Burch R, Sheikh H, Loder E. The prevalence, impact, and treatment of migraine and severe headaches in the United States: a review of statistics from national surveillance studies. Headache. 2013;53:427-436. doi:10.1111/head.12074.

29. Pope-Ford R, Jiang Z. Neck and shoulder muscle activation patterns among dentists during common dental procedures. Work. 2014;51:391-399.

30. Body Frame Work. http://www.bodyframework.com/about/. Accessed February 20, 2017.

31. Web MD. National Institute of arthritis and musculoskeletal and skin diseases. http://www.webmd.com/osteoarthritis/guide/national-institute-arthritis-musculoskeletal-skin-diseases. Accessed November 12, 2016

32. National Institute of Arthritis and Musculoskeletal and Skin Diseases. Handout on health: rheumatoid arthritis. http://www.niams.nih.gov/ Health_Info/Rheumatic_Disease/. Accessed November 8, 2016.

33. National Institutes of Health. Psoriatic arthritis. http://ghr.nlm.nih. gov/condition/psoriatic-arthritis. Accessed November 8, 2016.

34. American academy of orthopaedic surgeons. http://www.aaos. org/uploadedFiles/PreProduction/About/Opinion_Statements/ position/1113\%20Osteoporosis\%20Bone\%20Health\%20in\%20 Adults\%20as\%20a\%20National\%20Public\%20Health\%20Priority. pdf. Accessed October 1, 2016

35. National Institutes of Health. Osteoporosis in men. http://www. niams.nih.gov/Health_Info/Bone/Osteoporosis/men.asp. Accessed November 8, 2016

36. Gallup Poll. Majority in U.S. drink alcohol, averaging four drinks a week. http://www.gallup.com/poll/156770/majority-drink-alcohol-aver aging-four-drinks-week.aspx. Accessed September 6, 2016.

37. National Institute on Alcohol Abuse and Alcoholism. Alcohol facts and statistics. http://www.niaaa.nih.gov/alcohol-health/overview-alcohol-consumption/alcohol-facts-and-statistics. Accessed August 16, 2016.
38. National Institutes of Health. Alcohol alert. http://pubs.niaaa.nih.gov/ publications/aa32.htm. Accessed November 4, 2016

39. Health Day. Stress leads some doctors to abuse prescription drugs, study says. http://consumer.healthday.com/mental-health-information-25/addiction-news-6/stress-leads-some-doctors-to-abuse-prescription-drugs-681021.html. Accessed October 1, 2015.

40. Spine Health. Stress-related back pain. http://www.spine-health.com/ conditions/depression/stress-related-back-pain. Accessed December 6, 2015.

41. American Institute of Stress. Stress effects. http://www.stress.org/ stress-effects/. Accessed January 26, 2016.

42. Web MD. Reduce stress to prevent headaches. http://www.webmd. com/migraines-headaches/features/art-prevent-stress-headaches. Accessed May 8, 2016.

43. National Institute of Arthritis and Musculoskeletal and Skin Diseases. Handout on health: osteoarthritis. http://www.niams.nih.gov/Health_ info/Osteoarthritis/default.asp\#2. Accessed November 16, 2015.

44. National Cancer Institute. Psychological stress and cancer. http:// www.cancer.gov/cancertopics/factsheet/Risk/stress. Accessed September 16, 2015.

45. Nikolovska J, Mancevska S, Kapusevska B, Popovska L, Mindova S. An assessment of career satisfaction among Macedonian dentists. Prilozi. 2014;35:255-262.

46. Moore R, Brødsgaard I. Dentists' perceived stress and its relation to perceptions about anxious patients. Community Dent Oral Epidemiol. 2001;29:73-80.

47. Hakanen JJ, Perhoniemi R, Bakker AB. Crossover of exhaustion between dentists and dental nurses. Stress Health. 2014;30:110-121.

48. Myers HL, Myers LB. 'It's difficult being a dentist': stress and health in the general dental practitioner. Br Dent J. 2004;197:89-93. discussion 83; quiz 100-1.

49. Pozos-Radillo BE, Galván-Ramírez ML, Pando M, Carrión Mde L, González GJ. Comparative inter-institutional study of stress among dentists. Acta Odontol Latinoam. 2010;23:222-227.

50. Survey Gizmo. Survey response rates. https://www.surveygizmo. com/survey-blog/survey-response-rates/. Accessed November 17, 2016.

How to cite this article: Nalliah RP, Budd A, Allareddy V. Pilot survey of the health of Massachusetts dentists. J Invest Clin

Dent. 2017;8:e12263. https://doi.org/10.1111/jicd.12263 